\title{
SOME RELATIONS BETWEEN CERTAIN CLASSES OF ANALYTIC FUNCTIONS
}

\author{
Pranay Goswami, TeOdor BulboacĂ And SAnJAy K. BAnSAL
}

Abstract. In the present paper we introduce and studied two subclasses of multivalent functions denoted by $\mathscr{M}_{p, n}^{\lambda}(\gamma ; \beta)$ and $\mathscr{N}_{p, n}^{\lambda}(\mu, \eta ; \delta)$. Further, by giving specific values of the parameters of our main results, we will find some connection between these two classes, and moreover, several consequences of main results are also discussed.

Mathematics subject classification (2010): 30C45.

Keywords and phrases: Analytic functions, multivalent functions, starlike functions, convex functions, Bazilević functions..

\section{REFERENCES}

[1] H. IRMAK AND R. K. RAINA, The starlikeness and convexity of multivalent functions involving certain inequalities, Rev. Math. Complut., 16, 2 (2003), 391-398.

[2] H. Irmak, T. BulboacĂ And N. Tuneski, Some relations between certain classes consisting of $\alpha$-convex type and Bazilević type functions, Appl. Math. Lett., 24, 12 (2011), 2010-2014.

[3] S. S. Miller And P. T. Mocanu, Differential Subordinations. Theory and Applications, Series on Monographs and Textbooks in Pure and Applied Mathematics, Vol. 225, Marcel Dekker Inc., New York and Basel, 2000. 